This item was submitted to Loughborough's Research Repository by the author.

Items in Figshare are protected by copyright, with all rights reserved, unless otherwise indicated.

\title{
Human mismatches and preferences for automation
}

PLEASE CITE THE PUBLISHED VERSION

http://dx.doi.org/10.1080/00207540050204894

\section{PUBLISHER}

(c) Taylor and Francis

\section{VERSION}

AM (Accepted Manuscript)

\section{PUBLISHER STATEMENT}

This work is made available according to the conditions of the Creative Commons Attribution-NonCommercialNoDerivatives 4.0 International (CC BY-NC-ND 4.0) licence. Full details of this licence are available at: https://creativecommons.org/licenses/by-nc-nd/4.0/

\section{LICENCE}

CC BY-NC-ND 4.0

\section{REPOSITORY RECORD}

Rani, Mat R. Abdul, Murray A. Sinclair, and Keith Case. 2019. "Human Mismatches and Preferences for Automation". figshare. https://hdl.handle.net/2134/15815. 
International Journal of Production Research

38(17), 4033-4039, 2000

doi: $\underline{10.1080 / 00207540050204894}$

\title{
Human mismatches and preferences for automation
}

\author{
M. R. ABDUL RANI ${ }^{\dagger}$, M. A. SINCLAIR ${ }^{\ddagger}$ and K. CASE $\S^{*}$ \\ $†$ Faculty of Mechanical Engineering, Universiti Teknologi, Malaysia \\ $\ddagger$ Department of Human Sciences, Loughborough University, Loughborough, UK \\ $\S$ Wolfson School of Mechanical and Manufacturing Engineering, Loughborough \\ University, Loughborough, Leicestershire, LE11 3TU
}

\begin{abstract}
The research reported in this paper is concerned with gaining a better understanding of human factors issues in machining and the automation of manufacturing tasks. Mismatches between operators' performance and the requirements of machining tasks were experimentally studied in respect of relationships with various human characteristics including skill, age, work experience, self-confidence and trust. Twelve hypotheses concerning inter-relationships between these characteristics were evaluated and important relationships established. It is considered that this increased knowledge of the rate of mismatches and an understanding of the causes is essential for the successful design of new working environments, machines and tasks. Much of this change to the working environment is likely to involve some degree of automation of the operators' tasks and so a second and important aspect of the study was designed to establish the extent to which preferred levels of automation were related to the same human characteristics. Four further hypotheses relating preferred levels of automation to skill, age, work experience, self-confidence and trust were tested with results that in some cases were unexpected and in others contradict the findings of previous research.
\end{abstract}

\section{Introduction}

Mismatches between human performance and task requirements relate to incompatibilities, inappropriateness, unsuitabilities or inconsistencies which, if not addressed, would lead to errors. These mismatches have been experimentally studied in respect of their relationships with various human characteristics. The Human TaskMismatch Matching (HTMM) method was developed to study both mismatches and attitudes to automation in manual turning operations. The HTMM method uses experimental and questionnaire techniques and in this case it was applied to two groups consisting of 16 unskilled and 12 skilled operators. The skilled subjects were drawn from local industry and university technical staff, whilst all the unskilled subjects were engineering students who had some experience and knowledge of machining through periods of industrial placement. The human characteristics studied were level of skill, self-confidence, trust, work experience and age.

The experimental work involved each of the subjects being observed performing a simple but realistic machining task at their own machine in a familiar workplace (Figure 1). The mismatches studied are listed in table 1 and twelve hypotheses (table 2) were evaluated. 


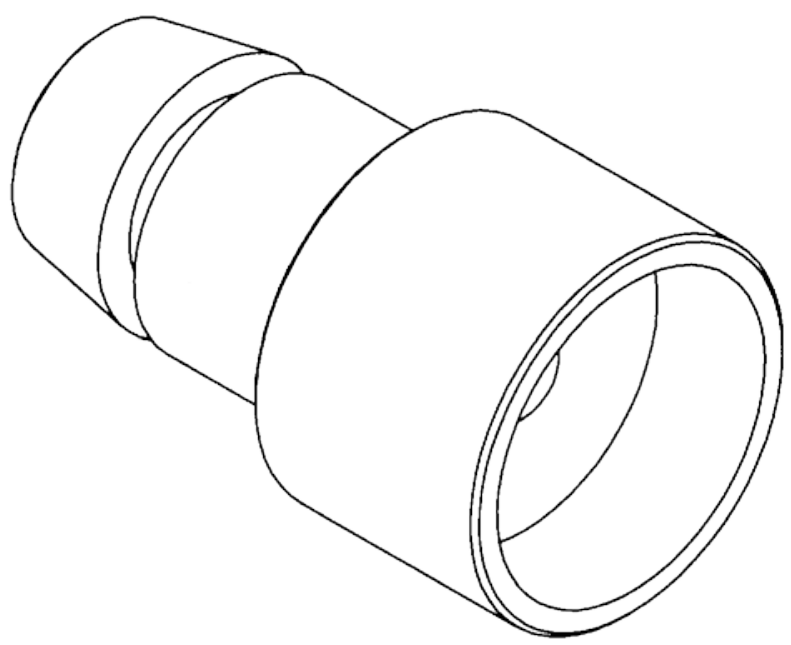

Figure 1. Test component for experimental study.

\begin{tabular}{ll}
\hline Intrusion & Help required in proceeding \\
Omission & A step omitted from the task \\
Commission & A step performed incorrectly \\
Reversal & Steps repeated due to earlier omission \\
Wrong request & For tools, etc. \\
Wrong components & Operating on incorrect components \\
Repetition & A step is unnecessarily repeated \\
Misapplication & Incorrect execution of a method \\
Violations & Standard procedures contravened \\
\hline
\end{tabular}

Table 1. The mismatches investigated

Mismatches

H1 More skilled operators commit fewer mismatches

H2 Operators having high self-confidence commit fewer mismatches

H3 Operators having a high level of trust commit fewer mismatches

H4 Operators with greater experience commit fewer mismatches

H5 Older operators commit fewer mismatches

Self-confidence

H6 More skilled operators have high self-confidence

H7 The higher the self-confidence, the higher the level of trust

H8 Operators with greater experience have more self-confidence

H9 Older operators have more self-confidence

Level of Trust

H10 More skilled operators have more trust

H11 Operators with greater experience have more trust

H12 Older operators have more trust

Table 2. Hypotheses evaluated by experimentation 


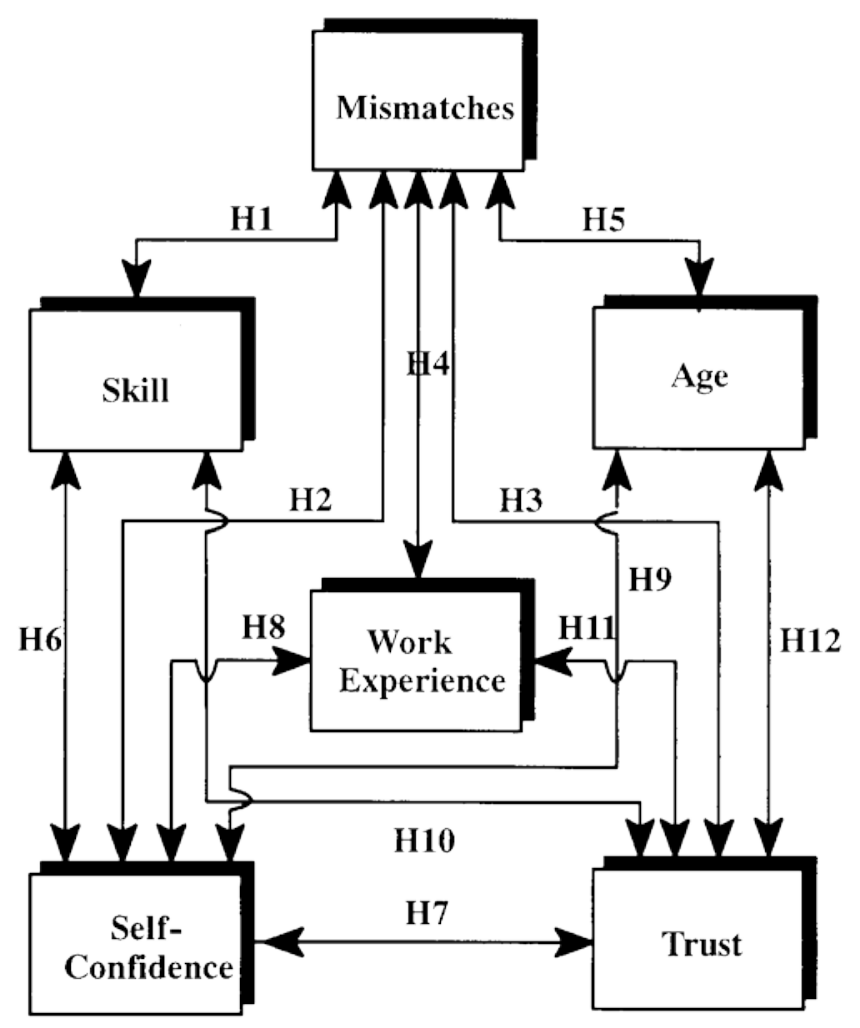

Figure 2. Hypotheses investigated by experimentation

Figure 2 illustrates the inter-relationships between the hypotheses. Analysis of the mismatches recorded revealed that for skilled operators repetition occurred most frequently whereas for unskilled operators intrusion (assistance sought) was most frequent. Statistically significant results were obtained for relationships under investigation, but only if the subjects were considered as a single group (i.e. regardless of skill level). The one exception to this was the significant relationship between selfconfidence and trust that was evident for skilled operators. Fuller details of the experimentation and results can be found in Case et al (1999).

In addition to this experimental work, the opportunity was taken to gain some understanding of attitudes to automation and this part of the study forms is emphasised in this paper. Relationships between the preferred level of automation (PLA) and the same human characteristics (i.e. self-confidence, trust, work experience and age) were investigated using a questionnaire survey as an integral part of the Human TaskMismatch Matching method (Abdul Rani, 1997).

In either manual or automated environments, it is generally accepted that the human operator still has an important function in the complete man-machine system (Rosenbrock, 1984). Imperfect interactions with machines leads to there being flaws in the tasks carried out by operators, and several potential discrepancies can arise between technical equipment and the human contribution to system performance. Generally, there is potential for a decrease in task performance, possible damage to the system and 
negative effects for the operator resulting from dissatisfaction, loss of self-confidence and lack of trust in the equipment (Lee and Moray, 1994).

Human operators have unpredictable aspects to their behaviour that may be responsible for unauthorised improvisations or even failures in undertaking tasks. In this uncertain situation various categories or levels of automation have been suggested in attempts to match users and the requirements of particular systems (Abdul Rani, 1997, Sheridan, 1994, Bright, 1956, Bell, 1972).

Human characteristics may have influence through subjective self-evaluative characteristics such as self-confidence (Bandura, 1977) and trust (Muir, 1994), and be related to work experience (Davies and Sparrow, 1985) or age (Robinson et al, 1984). Conversely, the level of automation in manufacturing may influence operators. For example higher levels of automation could reduce operator participation in manufacturing processes and in the extreme exclude the operator except for emergency situations. The skill and expertise acquired by operators might be lost through lack of use. Alternatively, lower levels of automation may create heavy demands for physical work that could lead to fatigue and over stress (Drury and Goonetillike, 1992). A systematic approach to creating choices for the preferred levels of automation is thus needed so that automation can be defined objectively.

\section{The Hypotheses and Model}

The model shown in figure 3 depicts the relationships between variables and these are formally defined below in a set of four hypotheses H1 - H4. These hypotheses have been developed after an extensive review of the literature on human problems in machining operations (Abdul Rani, 1997). The model resulting from these hypotheses is a path model linking the four latent variables into a path diagram.

H1: Operators with high self-confidence prefer lower levels of automation.

H2: Operators with higher levels of trust prefer lower levels of automation.

H3: Operators with longer working experience prefer lower levels of automation.

H4: Older operators prefer lower levels of automation.

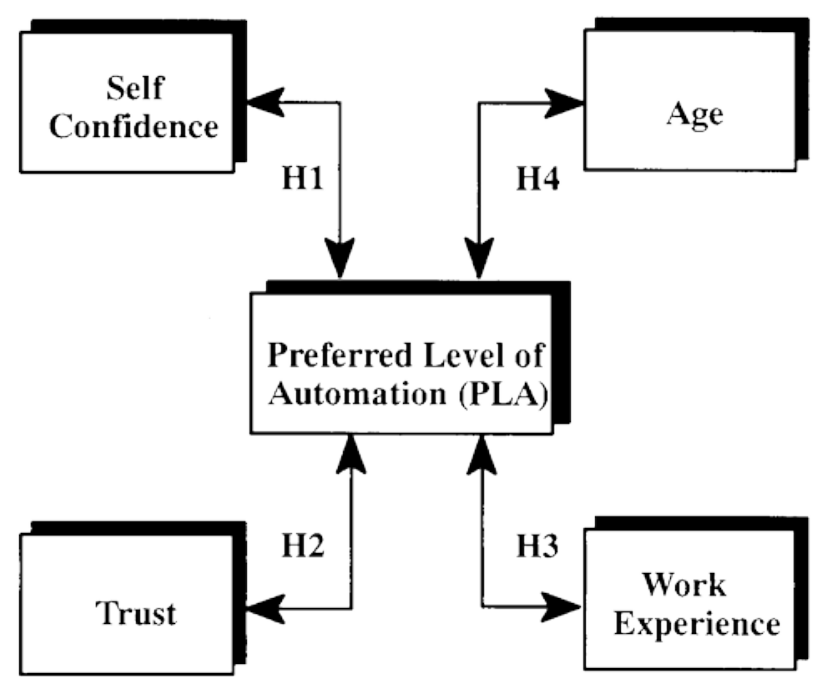

Figure 3. Hypotheses investigated by questionnaire. 


\section{Results}

H1: Operators with high self-confidence prefer lower levels of automation.

There is no relationship between self-confidence and Preferred Level of Automation (PLA) for skilled operators or for skilled and unskilled operators combined.

H2: Operators with a higher level of trust prefer a lower level of automation.

There is no relationship between level of trust and PLA for skilled operators or skilled and unskilled operators combined.

H3: Operators with longer working experience prefer lower levels of automation.

There is no relationship between the duration of work experience and PLA for skilled operators or skilled and unskilled operators combined.

H4: Older operators prefer lower levels of automation.

There is no relationship between age and PLA for skilled operators or skilled and unskilled operators combined.

\section{Discussion}

In this research the levels of automation consisted of a notional scale which was used to show a range of levels of automation in a particular system (Abdul Rani, 1997). The scale ranges between fully manual (1) and fully automated (10). The scale was used as a reference to establish if there were relationships between the preferred levels of automation (PLA) and the psychological (i.e. self-confidence, trust, working experience and age) human characteristics.

The scale was used in an attempt to determine the level of automation preferred by operators. This is essential considering that the broad spectrum of the level of automation is rather unspecific for both machine design and operator training procedures. The proper PLA is considered to be the basis on which to start the procedure of selecting the level of automation from a human perspective.

The results of hypothesis testing indicates that there were no relationships between the preferred levels of automation (PLA) and the psychological (self-confidence, trust, working experience and age) human characteristics. This lack of relationships between the preferred level of automation and self-confidence contradicts findings by Lee and Moray (1994) who suggested the use of automation when trust exceeded self-confidence and opted for manual control when self-confidence exceeded trust. Instead, the current findings suggest that operators having high self-confidence and trust might also prefer a high level of automation.

Furthermore, the absence of a relationship between PLA and trust, work experience and age may be due to operators' competency resulting in less reliance on machines to execute jobs. Even though a relationship between PLA and age is not established, the finding supplements current information which relates automation as a major change for older workers (Coberly and Morrison, 1984).

From the operator's perspective, the absence of relationships (PLA and selfconfidence, trust, work experience and age) suggest that operators' preferences are not related to the variables measured. However, it could be implied that automation (either low or high automation) may be viewed as unimportant to their tasks. In manufacturing, installing automation involves high capital costs that could be considered a waste if it is unacceptable to users. However, an optimum level of automation should be the ideal choice. 
Since there are no significant relationships between PLA and self-confidence, trust and work experience and age, based on the current study it is concluded that automation is not of particular importance in this respect and has no effect on operators. For turning operations, it could be recommended that a system should be designed with different levels of automation that could be selected by operators.

Findings in this study are in line with earlier findings (Drury and Goonetillike, 1992, Drakeford and Hardy, 1994) which suggested a decline in performance measures but an increase in stress with an increase in automation levels (except at the complete automation level). Drury and Goonetillike (1992) concluded that consistent performance benefits were virtually absent. Meanwhile, Drakeford and Hardy (1994) reported an example of limited success of automation based on actual manufacturing processes.

\section{Conclusions}

No relationship was found between the Preferred Level of Automation and the selected human characteristics. In some instances this may be regarded as unexpected as it for example demonstrates that older workers are no less receptive to the idea of automation than their younger counterparts.

The overall conclusion reached is that the relating performance and subjective aspects to human characteristics is a difficult task, but the insight gained can be useful in planning future manufacturing facilities.

With respect to turning operations and for both groups of operators, skilled, and skilled and unskilled operators combined, no relationship exists between, (a) preferred levels of automation and self-confidence, (b) preferred levels of automation and trust, (c) preferred levels of automation and working experience or (d) preferred levels of automation and age.

In the light of this study, there is evidence that a total preference for total automation does not exist (in contrast to the common and informal belief). The absence of relationships between the variables reinforces suggestions that humans, machines and tasks contribute to human-machine symbiosis. Further work is needed towards the development of the preferred levels of automation for manufacturing activities or processes.

\section{References}

ABDUL RANI, M. R., 1997, Human Mismatches in Machining, PhD Thesis. Loughborough University, UK.

BANDURA, A., 1977, Self-efficacy: toward a unifying theory of behavioral change, Psychological Review, 84(2), 191-215.

BELL, M., 1972, Changing Technology and Manpower Requirements in the Changing Industry. (Sussex University Press).

BRIGHT, J., 1956, Automation and Management, (Cambridge, MA: Cambridge University Press).

CASE, K., SINCLAIR, M. A. and ABDUL RANI, M. R., 1999, An experimental investigation of human mismatches in machining, Proceedings of the Institution of Mechanical Engineers, Part B Journal of Manufacturing, 213, 197-201.

COBERLY, S., and MORRISON, M., 1984, Aging and technological advances: labour force participation, in Aging and Technological Advances, edited by P. K. Robinson, J. Livingston and J. E. Birren, (Plenum Press).

DAVIES, D. R. and SPARROW, P. R., 1985, Age and Behaviour. In Ageing and Human Performance, edited by N. Charness (Wiley). 
DRAKEFORD, D. C. and HARDY, S. J., 1994, Automation in a workforce environment, Factory 2000-Advanced Factory Automation, 3-5 October 1994, Conference Publication No. 398, pp. 387-393.

DRURY, C. G. and GOONETILLIKE, R. S., 1992, Stress, performance and level of automation: a controlled study. In Contemporary Ergonomics, Proceedings of the Ergonomics Society's Annual Conference, edited by E. J. Lovesay, Birmingham, England, 7-10 April 1992 (Taylor \& Francis), pp. 131-136.

LEE, J. D. and MORAY, N., 1994, Trust, self-confidence and operators' adaptation to automation. International Journal of Human-Computer Studies. 1, 153-184.

MUIR, B. M., 1994, Trust in automation: Part I. Theoretical issues in the study and human intervention in automated systems, Ergonomics, 37(11), 1905-1922.

ROBINSON, G. H., NADLER, G. and PETERSON, J. G., 1984, People in future factories and offices: with an introduction to some special opportunities and problems for an aging workforce. In Aging and Technological Advances, edited by P. K. Robinson, J., Livingston and J. E. Birren ( Plenum Press).

ROSENBROCK, H. H., 1984, Designing automated systems - need skill be lost? In New Technology and the Future of Work and Skills, edited by P. Marstrand (London:Pinter).

SHERIDAN, T. B., 1994, Human supervisory control. In Design of Work and Development of Personnel in Advanced Manufacturing, edited by G. Salvendy, and W. Karwowski (USA:Wiley). 